\title{
Burden of Cancers Related to Smoking among the Indonesian Population: Premature Mortality Costs and Years of Potential Life Lost
}

\author{
Susi Ari Kristina ${ }^{1 *}$, Dwi Endarti', Yayi Suryo Prabandari², Abdillah Ahsan ${ }^{3}$, \\ Montarat Thavorncharoensap ${ }^{4}$
}

\begin{abstract}
Background: As smoking is the leading preventable cause of multiple diseases and premature cancer deaths, estimating the burden of cancer attributable to smoking has become the standard in documenting the adverse impact of smoking. In Indonesia, there is a dearth of studies assessing the economic costs of cancers related to smoking. This study aimed to estimate indirect mortality costs of premature cancer deaths and years of potential life lost (YPLL) attributable to smoking among the Indonesian population. Materials and Methods: A prevalence based method was employed. Using national data, we estimated smoking-attributable cancer mortality in 2013. Premature mortality costs and YPLL were estimated by calculating number of cancer deaths, life expectancy, annual income, and workforce participation rate. A human capital approach was used to calculate the present value of lifetime earnings (PVLE). A discount rate of 3\% was applied. Results: The study estimated that smoking attributable cancer mortality was 74,440 (30.6\% of total cancer deaths), comprised of $95 \%$ deaths in men and $5 \%$ in women. Cancers attributed to smoking wereresponsible for 1,207,845 YPLL. Cancer mortality costs caused by smoking accounted for USD 1,309 million in 2013. Among all cancers, lung cancer is the leading cause of death and economic burden. Conclusions: Cancers related to smoking pose an enormous economic burden in Indonesia. Therefore, tobacco control efforts need to be prioritized in order to prevent more losses to the nation. The data of this study are important for advocating national tobacco control policy.
\end{abstract}

Keywords: Smoking - cancer - YPLL - premature mortality cost - Indonesia

Asian Pac J Cancer Prev, 16 (16), 6903-6908

\section{Introduction}

Smoking is considered to be an important cause of premature cancer mortality and disability. In 2008, about 7.6 million people worldwide have died due to cancers (Ferlay et al., 2010). By 2030, it is projected that there will be 26 million new cancer cases and 17 million cancer deaths per year (Ezzati and Lopez, 2004). The burden of cancer study currently is being held in ASEAN region, including Indonesia that involve 10,000 newly diagnosed patients with cancer, in order to assess the health and socioeconomic impact of cancer (Jan et al., 2012). Smoking is regarded as one of the most important risk factors causes various types of cancers (Mathers et al., 2008). Based on GLOBOCAN data, about 271,211 people in Southeast Asia have died from cancer in 2008 (Kimman et al., 2012).

To reduce mortality of cancers, implementing the universal coverage especially in lower middle income countries like Indonesia must be encouraged (Akaza et al., 2015). Currently cancer is major concerns of public health in Indonesia due to the high cost of treatment and substantial burden to the national budget since universal coverage has been applied in 2014. In fact, Indonesian smokers is highest among ASEAN countries (Lian and Dorotheo, 2013) and the country recently is not ratify WHO FCTC and there is no restrict legislations to protect nonsmokers (WHO Framework Convention on Tobacco Control, 2014).

It has been identified several preventive measures that most feasible approach to mitigate the global increase in cancer in developing countries. Foremost among these are the need to strengthen efforts in tobacco control (Thun et al., 2010). Presenting the data on smoking impacts into monetary values is important to advocate government in implementing national tobacco control initiatives. Important indicator developed by WHO in this way is the Economics of tobacco toolkit on the assessment of the economic costs of smoking (World Health Organization, 2011a). Focus on mortality data, this includes smoking

${ }^{1}$ Management and Community Pharmacy Division, Faculty of Pharmacy, ${ }^{2}$ Public Health Department, Faculty of Medicine, Gadjah Mada University, Yogyakarta, ${ }^{3}$ Demographic Institute, Faculty of Economics, University of Indonesia, Jakarta, , Indonesia, ${ }^{4}$ Social and Administrative Pharmacy Department, Faculty of Pharmacy, Mahidol University, Bangkok, Thailand *For correspondence: susiarikristina@gmail.com 
attributable fractions, mortality rate, Years potential life lost (YPLL) and smoking attributable mortality costs (SAMC). Burden of cancer is considered very crucial in economics (Hanly et al., 2014) and measuring the mortality costs of cancers related to smoking is very important for country that the prevalence of smoking is high

In Indonesia, at first time, economic cost study has been conducted in 2008, resulted 602,350 deaths due to diseases attributed to smoking or almost one third of the estimated total deaths in the same year, and DALYs loss of $13,066,230$ or $25.5 \%$ of total DALYs loss in the same year and at the macro level, the DALYs loss caused economic loss of 18.5 billion USD (National Institute of Health Research and Development (NIHRD), 2009). In our study, a first attempt for Indonesia setting, an analysis of the cancer due to smoking mortality costs employed an updated epidemiological data and national monetary data was undertaken. This study aimed to estimate the indirect mortality costs attributable to smoking and YPLL in cancers among Indonesian population in 2013.

\section{Materials and Methods}

In the present study, the prevalence-based, diseasespecific approach was applied to estimate the cancers mortality attributed to smoking, premature cancer mortality costs attributed to smoking, and years of potential life lost (YPLL) from human capital perspective. The 11 cancers related to smoking were considered to be included based on national data availability and the SAF was used to estimate the number of cancer deaths due to smoking.

\section{Data sources}

Smoking prevalence: the smoking prevalence was obtained from secondary data of Basic Health Survey 2013 that has been collected from 33 provinces and 497 districts/municipalities. Respondents were consisted of 300,000 household samples. Data were collected via household interview during Mei-June 2013 (Ministry of Health, 2013).

Relative risks: The relative risks of target cancers for smokers were obtained from published article as described in Table 1 (Gandini et al., 2008).
Number of deaths for each cancer: country information of adult mortality was predicted from NIHRD (National Institute of Health and Research Development) were used. The number of deaths by age and sex were derived from the study that has been conducted in five public general hospitals namely Dharmais Cancer Hospital Jakarta, Persahabatan Hospital Jakarta, Soetomo Provincial Hospital Surabaya, Sardjito Provincial Hospital Yogyakarta, and Sanglah General Hospital Denpasar (National Institute of Health Research and Development (NIHRD), 2009).

Calculation of smoking attributable mortality (SAM) and smoking attributable fraction (SAF)

Sex and age-specific smoking attributable mortality (SAM): SAM were calculated by multiplying the total number of deaths (by age 15-59, 60-80, and >80 years old) for 11 cancer sites by the smoking attributable fraction (SAF) of each cancer site.

Smoking attributable fraction (SAF\%): the attributable fractions provides estimates of the public health burden of each risk factor and relative importance of risk factor for multifactorial diseases (Mathers CD, 2001). The disease specific SAF were derived using sex-specific relative risk (RR) estimated from meta-analysis (Gandini et al., 2008). SAF formula is as follow (World Health Organization, 2011a):

$$
\operatorname{SAFi}(\%)=100 *\left(\frac{\mathrm{p}(\mathrm{RRi}-1)}{(1+\mathrm{p}(\mathrm{RRi}-1)}\right)
$$

Where "p" denotes the smoking prevalence rate and "RR" denotes the relative risk of the disease of interest.

\section{Calculation of the YPLL and SAMC}

Cancers due to smoking YPLLs and premature mortality costs: were estimated by multiplying sex-and age-specific cancer deaths remaining life expectancy (World Health Organization, 2010) and lifetime earnings data (National Bureau of Statistics, 2013)

In addition, demographic data was based on population census 2010 conducted by National Statistics Bureau and its projection for 2013 was used to calculate $\%$ of workforce participation as a factor to derives lifetime earning data.

Table 1. The Relative Risks and Smoking-Attributable Fractions (SAF) of Cancers

\begin{tabular}{|c|c|c|c|c|c|}
\hline \multirow[t]{2}{*}{ ICD-10 } & \multirow[t]{2}{*}{ Cancer site } & \multicolumn{2}{|c|}{ Relative risks } & \multicolumn{2}{|c|}{$\operatorname{SAF}(\%)$} \\
\hline & & Male & Female & Male & Female \\
\hline $\mathrm{C} 00-\mathrm{C} 14$ & Mouth \& oropharynx & 3.52 & 3.8 & 62.09 & 5.55 \\
\hline $\mathrm{C} 15$ & Oesophagus & 2.52 & 2.28 & 49.7 & 2.62 \\
\hline $\mathrm{C} 16$ & Stomach & 1.74 & 1.45 & 32.48 & 0.94 \\
\hline $\mathrm{C} 22$ & Kidney & 1.59 & 1.35 & 27.72 & 0.73 \\
\hline $\mathrm{C} 25$ & Liver & 1.85 & 1.49 & 35.59 & 1.02 \\
\hline C32 & Pancreas & 1.63 & 1.73 & 29.05 & 1.51 \\
\hline C33-C34 & Lung & 9.87 & 7.58 & 85.21 & 12.14 \\
\hline C53 & Larynx & 6.98 & 6.98 & 79.54 & 11.16 \\
\hline C64-C65 & Cervix uteri & - & 1.83 & - & 1.71 \\
\hline C67 & Bladder & 2.8 & 2.73 & 53.92 & 3.51 \\
\hline C92.0 & Myeloid monocytic leukemia & 1.09 & 1.09 & 5.53 & 0.19 \\
\hline
\end{tabular}


Burden of Cancers Related to Smoking among Indonesians: Premature Mortality Costs and Years of Potential Life Lost

The study was approved by Medical and Health Research Ethics Committee (MHREC) on July 2014 at the University of Gadjah Mada with approval number $\mathrm{KE} / \mathrm{FK} / 808 / \mathrm{EC}$.

\section{Results}

The cancer relative risks and smoking-attributable fractions (SAF) are shown in Table 1. In male, lung cancer showed the greatest SAF (85.21\%), while in female's lung cancer was $12.14 \%$ attributable to smoking, followed by larynx cancer $(69.54 \%$ and $11.16 \%$ for male and female respectively) and mouth \& oropharynx cancer $(62.09 \%$ and $5.55 \%$ for male and female respectively). In all cancers the SAFs were found to be substantially higher in male than in female because of the prevalence of smoking in Indonesia was higher in male rather than in female $(67.4 \%$ are male smokers and $4.5 \%$ are female smokers).

The estimated numbers of deaths attributable to smoking are summarized in Table 2. During 2013, an estimated 74,440 people in Indonesia died prematurely as a result of cancers attributable to smoking, accounted for $30.6 \%$ of the total cancer deaths. The proportion of adult deaths attributable to smoking was $95 \%$ for men and $5 \%$ for women respectively, following the smoking prevalence that higher in male. The data delineated three leading cancer deaths attributable to smoking were lung cancer
$34,786(46.7 \%), 12,278(16.5 \%)$ by mouth \& oropharynx cancer and $10,714(14.4 \%)$ by liver cancer.

As shown in Table 2, all YPLL due to 11 major cancers amounted to 1,145,988 for males and 61,856 for females, and accounted for $95 \%$ and $5 \%$ of YPLL for males and females, respectively. Both for males and females, the YPLL due to lung cancer, mouth \& oropharynx cancer, and liver cancer were the three highest. Because of the high mortality rate in the 35-59 age group, it is reasonable to see that this age group had the highest YPLL. Therefore, we need to pay more attention to the prevention of cancer deaths due to smoking for males in this age group, because their productivity will be lost. When we examined closely, we found that these lung cancer, mouth \& oropharynx cancer, and liver cancer deaths among male were about $78 \%$ of the YPLL total. We also found that about $77 \%$ of YPLL among female was due to mouth, lung, and cervix uteri cancer.

Table 3 shows smoking attributable mortality costs (SAMC) of cancers in 2013. Estimates for year 2013 cancers SAMC were approximately USD 1,309 million, consisted of USD 1,280 million for males and USD 29 million for females. The three leading smoking attributable cancers in terms of mortality costs were lung cancer (USD 621 million ), mouth \& oropharynx cancer (USD 215 million), and liver cancer (USD 193 million) in both sexes combined.

Table 2. Number of Cancer Deaths Attributable to Smoking and Years of Potential life losts (YPLLs) in Indonesia 2013

\begin{tabular}{|c|c|c|c|c|c|c|c|}
\hline \multirow[t]{2}{*}{ ICD-10 } & \multirow[t]{2}{*}{ Cancer site } & \multicolumn{6}{|c|}{ Death attributable to smoking YPLL } \\
\hline & & Male & Female & Total & Male & Female & Total \\
\hline $\mathrm{C} 00-\mathrm{C} 14$ & Mouth \& oropharynx & 11,312 & 966 & 12,278 & 184,842 & 17,706 & 202,547 \\
\hline $\mathrm{C} 15$ & Oesophagus & 3,417 & 124 & 3,541 & 55,831 & 2,276 & 58,107 \\
\hline $\mathrm{C} 16$ & Stomach & 4,670 & 228 & 4,898 & 76,307 & 4,185 & 80,492 \\
\hline $\mathrm{C} 22$ & Kidney & 54 & 0 & 54 & 887 & 0 & 887 \\
\hline $\mathrm{C} 25$ & Liver & 10,466 & 248 & 10,714 & 171,024 & 4,536 & 175,560 \\
\hline $\mathrm{C} 32$ & Pancreas & 0 & 31 & 31 & 0 & 584 & 584 \\
\hline C33-C34 & Lung & 33,453 & 1,333 & 34,786 & 546,611 & 24,426 & 571,037 \\
\hline C53 & Larynx & 3,120 & 80 & 3,200 & 35,763 & 1,468 & 37,232 \\
\hline C64-C65 & Cervix uteri & 0 & 293 & 293 & 0 & 5,360 & 5,360 \\
\hline C67 & Bladder & 4,267 & 56 & 4,323 & 69,724 & 1,030 & 70,755 \\
\hline C92.0 & Myeloid monocytic leukemia & 306 & 16 & 322 & 4,999 & 285 & 5,284 \\
\hline Total & & 71,065 & 3375 & 74,440 & $1,145,988$ & 61,856 & $1,207,845$ \\
\hline
\end{tabular}

Table 3. Smoking Attributable Mortality Costs (SAMC) for Cancers in Indonesia 2013

\begin{tabular}{llrrr}
\hline CD-10 & \multicolumn{1}{c}{ Cancer site } & \multicolumn{2}{c}{ SAMC (USD) } \\
\cline { 3 - 4 } & & \multicolumn{1}{c}{ Male } & Female & Total \\
\hline C00-C14 & Mouth \& oropharynx & $206,203,797$ & $8,446,093$ & $214,649,890$ \\
C15 & Oesophagus & $62,283,179$ & $1,085,651$ & $63,368,830$ \\
C16 & Stomach & $85,125,033$ & $1,996,556$ & $87,121,589$ \\
C22 & Kidney & 989,316 & - & 989,316 \\
C25 & Liver & $190,788,698$ & - & $192,952,318$ \\
C32 & Pancreas & $609,781,722$ & 278,499 \\
C33-C34 & Lung & $41,757,704$ & 278,499 & $621,433,642$ \\
C53 & Larynx & - & $11,651,921$ & $42,458,102$ \\
C64-C65 & Cervix uteri & $77,782,163$ & 700,397 & $2,556,821$ \\
C67 & Bladder & $5,576,512$ & $2,556,821$ & $78,273,554$ \\
C92.0 & Myeloid monocytic leukemia & $1,280,288,124$ & 491,391 & $5,712,230$ \\
Total (USD) & & 135,717 & $1,309,794,790$ \\
\hline
\end{tabular}

*USD $1=$ IDR 11,325 as per average exchange rate for the year 2013 as per world bank. Available at http://data.worldbank.org/indicator/PA.NUS.PPP.05 
Table 4. Sensitivity Analysis of Smoking Prevalence and Saf and Number of Deaths Attributable to Smoking And Premature Mortality Costs

\begin{tabular}{|c|c|c|c|c|c|c|}
\hline \multirow[t]{2}{*}{ Analysis and varible } & \multicolumn{2}{|c|}{ Prevalence } & \multicolumn{2}{|c|}{ SAF } & \multicolumn{2}{|c|}{$\begin{array}{l}\text { Number of deaths } \\
\text { attributable to smoking }\end{array}$} \\
\hline & Male & Female & Male & Female & Male & Female \\
\hline Main Analysis & $64.90 \%$ & $2.10 \%$ & 0.48 & 0.03 & 146,176 & 7,520 \\
\hline \multicolumn{7}{|l|}{ Sensitivity analysis: Prevalence increase } \\
\hline $10 \%$ & $71.50 \%$ & $2.31 \%$ & 0.5 & 0.04 & 152,270 & 10,027 \\
\hline $15 \%$ & $74.75 \%$ & $2.41 \%$ & 0.51 & 0.04 & 155,315 & 10,027 \\
\hline $20 \%$ & $78 \%$ & $2.52 \%$ & 0.52 & 0.04 & 158,361 & 10,027 \\
\hline $25 \%$ & $81.25 \%$ & $2.62 \%$ & 0.53 & 0.04 & 161,406 & 10,027 \\
\hline \multicolumn{7}{|l|}{ Prevalence decrease } \\
\hline $1 \%$ & $58.50 \%$ & $1.89 \%$ & 0.48 & 0.03 & 146,176 & 7,520 \\
\hline
\end{tabular}

The top three of premature mortality costs in male were lung cancer (USD 609 million), mouth \& oropharynx cancer ( USD 206 million), and liver cancer (USD 191 million). In female, the leading premature costs was lung cancer (USD 11.6 million), followed by mouth \& oropharynx (USD 8.4 million) and liver cancers (USD 2.1 million). The total premature cost in male was 45 times higher than that of female.

\section{Sensitivity analysis}

Table 4 shows that if the prevalence rates of smoking in 2013 had increased $10 \%$, the SAFs would have been greater by 0.02 point for male and 0.01 point for female. Additional 6,094 deaths and 2,507 deaths for male and female respectively would be occurred. If the prevalence rates of smoking were at 1\% decreasing of the 2013 prevalence, there would have no significant reduction in number of deaths attributable to smoking both for male and female.

\section{Discussion}

This study was the first attempt in estimating the burden of cancers attributable to smoking in Indonesia. Smoking is currently a very important determinant of mortality among Indonesian $(74,440)$, accounted for $30.6 \%$ of total cancer deaths (National Institute of Health Research and Development (NIHRD), 2009) and 7.23\% of national total deaths (World Health Organization, 2011b). However, the proportion of cancer deaths caused by smoking exhibited large variations among different sex (for men $95 \%$ of total cancer mortality and female 5 $\%$ of total cancer mortality). In addition, the number of smoking-attributable cancer deaths varies according to trend in the number of deaths from cancer itself.

This figure is lower than another country such as US (443,000 deaths in 2004) (Centers for Disease Control and Prevention (CDC), 2008) and China (552,280 deaths in 2008) (Yang et al., 2011). The differences occur because the shape and maturity of the smoking epidemic is highly affected by region-specific socioeconomic and cultural determinants of smoking, as well as because background mortality varies across populations.

The different pattern in the variety of cancer death was captured in this study if compared with other countries. For example Iranian study found that stomach cancer, lung cancer, and prostate cancer were the leading cancer deaths (Khorasani et al., 2015). In Korea, tobacco smoking was responsible for $71 \%$ of lung cancer deaths, $55-72 \%$ of upper aerodigestive tract (including oral cavity, pharynx, oesophagus and larynx) and $32 \%$ of stomach cancer deaths (Park et al., 2014)

It predicts that the number of smoking-attributable cancer deaths will remain high and relatively unchanged, primarily because of increases in population size (particularly among older age groups). At present, cohort of smokers with highest peak prevalence still not reached the ages with highest incidence of smoking attributable diseases especially in cancer and others noncommunicable diseases, therefore the highest prevalence of these deaths will be occurr in the next 20-30 years. Currently, non-communicable diseases (NCDs) account for $63 \%$ of total deaths in Indonesia (World Health Organization, 2011b). In the case of Indonesia, cancers have the largest contribution NCDs mortality. Hence, the country is still clearly grappling with a double burden of disease. Given that health spending in Indonesia is a mere $1.3 \%$ of GDP (World Bank, 2011).

The findings were similar to other studies that found lung cancer make up a much larger proportion of total smoking-attributable deaths (Sung et al., 2006; Park et al., 2014). However, it should be acknowledged that regional differences in nutritional, behavioral, and environmental factors and medical care, makes different in the trend of diseases' risk factors. Parallel to changes in these risk factors, smoking increased substantially in most developing countries over the last quarter of the twentieth century, with an estimated 930 million of the world's 1.1 billion smokers currently living in the developing world (World Health Organization, 2012).

Compared to the earlier estimations on SAFs in Indonesia (National Institute of Health Research and Development (NIHRD), 2009), this study represents a major improvement in two ways. First, the RR of current smokers versus non-smokers was provided by recent published articles that provided comprehensive smoking exposure and mortality data. Second, the prevalence rate of smoking among male and female came from the current Basic Health Survey database. These data represented the $95 \%$ of the total population. Therefore the current estimation of SAFs was more precise. Smoking attributable fractions are highest for lung cancers, larynx 
Burden of Cancers Related to Smoking among Indonesians: Premature Mortality Costs and Years of Potential Life Lost

and mouth \& oropharynx, ; however, because of the absolute number of deaths were highest for lung cancer, mouth \& oropharynx, and liver cancer, it contributes a large number of smoking-attributable deaths.

Productivity lost presented by years of potential life lost show that YPLL total accounted for an estimated $1,207,845$ in total YPLL. Most smoking attributable YPLL were related to lung cancer, mouth \& oropharynx cancer and liver cancer. A huge number of Indonesian YPLL captures substantial potential lost productivity due to cancer mortality attributable to smoking. Similar findings were highlighted by Korean study, that the most leading years with disability due to smoking were lung cancers (366 DALY) and liver cancers (341.6 DALY) (Oh et al., 2012).

The results of the present study show that cancers due to smoking cost the Indonesia economy an estimated USD 1,309 million in 2013, comprised of USD 1,280 million for male and USD 29.5 million for female. Lung cancer was the leading cause of smoking attributable mortality costs. These findings were in line with Korean data that the most costly were lung cancer, followed by liver cancers and stomach cancer (Oh et al., 2012). Because of higher YPLL and higher labor force participation rates, it is not surprising that the male group accounted for much of the cost. Similar pattern was found in Iranian study (Khorasani et al., 2015) that cost of cancers among male was higher than female counterpart. Although we neglected the income from the underground economy and opportunity cost of housekeeping would underestimate the cost of premature death for females, it is not a major problem in this study because most of the SAFs for females are zero or trivial.

This study confirms that the highest prevalence of smoking in Indonesia among ASEAN countries imposes a substantial economic burden as well as a considerable public health impact.

The findings in this report are subject to limitations. First, the estimates understate cancer deaths attributable to tobacco use because did not take into acount former smokers. Estimates of cancer deaths attributable to pipe smoking and smokeless tobacco use were also unavailable. Second, RRs were based on published studies in developed world which was might have had different smoking histories such as age of initiation and duration of smoking before quitting, rather than current or former smokers. Third, this report used mortality data from 5 hospitals only, therefore mortality of attributable to smoking might be underestimate. Uncertainty nonetheless remains, especially in Indonesia where both complete mortality records and detailed studies of disease risk factors are less common. Therefore, comparing the results from previous studies that used similar approaches to quantify the economic impacts of smoking is needed. Moreover, premature mortality costs understate the total costs of cancer due smoking because costs associated with cancer-related disability, health care expenditure in cancer treatment were not included.

In conclusion, cigarette smoking continues to impose substantial health and financial costs on the society. The prevalence based, disease-specific analysis described here shows clearly that the health and economic impact of cancers attributed to smoking in Indonesia are very dramatic, and should be reduced by implementing smoking cessation and related tobacco control policies in order to reducing the high prevalence of smoking in Indonesia.

\section{Acknowledgements}

The authors wish to thank the John Hopkins School of Public Health and Muhammadiyah Tobacco Control Center for support funding. We would also like to thank Dr. Soewarta Kosen and National Bureau of Statistics for providing the epidemiology data and National Wages Workforce data.

\section{References}

Akaza H, Kawahara K, Nozaki S, et al (2015). Roundtable discussion at the UICC World Cancer Congress: Looking toward the realization of universal health coverage for cancer in Asia. Asian Pac J Cancer Prev, 16, 1-8.

Centers for Disease Control and Prevention (CDC) (2008). Smoking-attributable mortality, years of potential life lost, and productivity losses-United States, 2000-2004. MMWR Weekly, 57, 1226-8.

Ezzati M,Lopez AD (2004). Regional, disease-specific patterns of smoking attributable mortality in 2000. Tob Control, 13, 388-94.

Ferlay J, Shin HR, Bray F, et al (2010). Estimates of worldwide burden of cancer in 2008: GLOBOCAN 2008. Int J Cancer, 127, 2893-917.

Gandini S, Botteri E, Iodice S, et al (2008). Tobacco smoking and cancer: A meta-analysis. Int J Cancer, 122, 155-64.

Hanly P, Pearce A, Sharp L (2014). The cost of premature cancerrelated mortality: a review and assessment of the evidence. Expert Rev Pharmacoeconomics Out Res, 1-23.

Jan S, Kimman M, Kingston D, et al (2012). The socioeconomic burden of cancer in member countries of the Association of Southeast Asian Nations (ASEAN) - Stakeholder meeting report. Asian Pac J Cancer Prev, 13, 407-9.

Khorasani S, Rezaei S, Rashidian H, et al (2015). Years of potential life lost and productivity costs due to premature cancer-related mortality in Iran. Asian Pac J Cancer Prev, 16, 1845-50.

Kimman M, R N, Jan S, et al (2012). The burden of cancer in member countries of the Association of Southeast Asian Nations (ASEAN). Asian Pac J Cancer Prev, 13, 411-20.

Mathers CD VT, Lopez AD, Salomon J, Ezzati M (ed.) 2001. National Burden of Disease Studies: A Practical Guide, Geneva: World Health Organization.

Oh I, Yoon S, Yoon T, et al (2012). Health and economic burden of major cancers due to smoking in Korea. Asian Pac J Cancer Prev, 13, 1525-31.

Park S, Jee SH, Shin H, et al (2014). Attributable fraction of tobacco smoking on cancer using population-based nationwide cancer incidence and mortality data in Korea. BMC Cancer, 14.

Sung HY, Wang L, Jin S, et al (2006). Economic burden of smoking in China, 2000. Tobacco Control, 15, 5-11.

Thun MJ, DeLancey JO, Center MM, et al (2010). The global burden of cancer: priorities for prevention. Carcinogenesis, 31, 100-10.

World Health Organization. 2010. Global Health Observatory Data Repository. LIfe expectancy: Life tables Indonesia 
Susi Ari Kristina et al

[Online]. Geneva: WHO.

Yang L, Sung H, Mao Z, et al (2011). Economic costs attributable to smoking in China: Update and an 8-year comparison, 2000-2008. Tob Control, 20, 266-72. 